\title{
A COVID-19 Patient Which is Diagnosed after Magnetic Resonance Imaging
}

Uğur Kesimal (D)

Department of Radyoloji, Recep Tayyip Erdoğan University Training and Research Hospital, Rize, Turkey

A 40-year-old female patient without any medical history presented to the emergency department with a 3-day history of neck pain and headache. She did not show any other symptoms. Her initial laboratory tests showed slightly increased C-reactive protein ( $6 \mathrm{mg} / \mathrm{L}$; normal range $0-5 \mathrm{mg} / \mathrm{L}$ ) and a normal white cell count. There were not observed any other abnormal laboratory finding (leukocyte, 7.4 x 103/uL; hemoglobin, 11.7 gr/dL; platelet, 172 x 103/uL; aspartate aminotransferase, $27 \mathrm{U} / \mathrm{L}$; alanine aminotransferase, $31 \mathrm{U} / \mathrm{L})$. After her neurological examinations, she

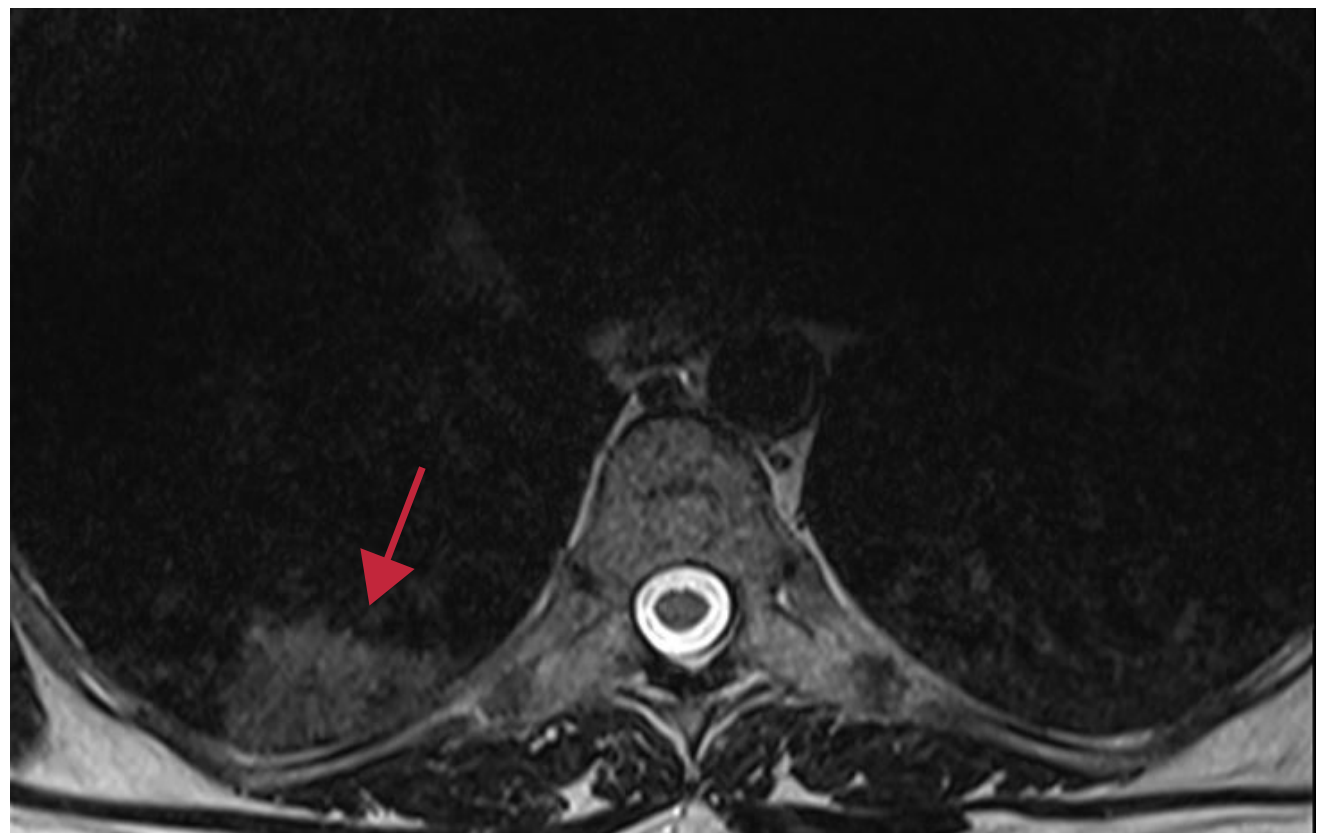

Corresponding Author: Uğur Kesimal

E-mail:

ugur_kesimal@hotmail.com

Received: September 20, 2020 Accepted: November 14, 2020 Published: December 31, 2020

\section{Suggested citation:}

Kesimal U. A COVID-19 Patient Which is Diagnosed after Magnetic Resonance Imaging. Infect Dis Clin Microbiol 2020; 3 : 179-180.

Figure 1. 


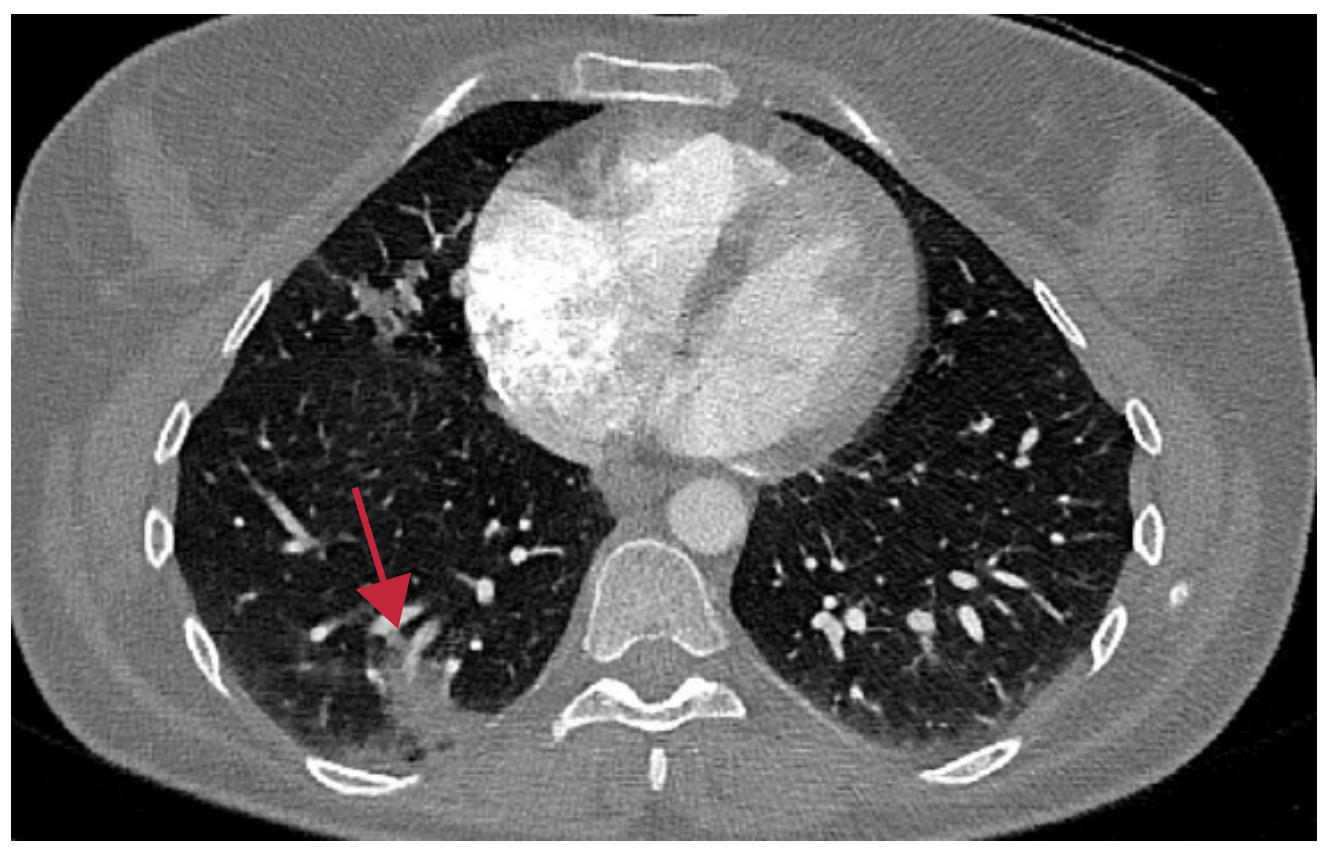

Figure 2.

was hospitalized for further management. She was evaluated with brain and spine MRI to determine neurologic etiologies. The thoracic spine magnetic resonance imaging demonstrated $\mathrm{T} 2$ hyperintense right-sided focal lung infiltration (Figure I). The suspicious finding was reported to the referring physician immediately. She was investigated with chest computed tomography for further investigation of this finding. Tomography showed consolidation in the lower lobe of the right lung (Figure II). The differential diagnosis of radiological findings includes viral pneumonia, atypical bacterial pneumonia, pulmonary edema, interstitial lung disease, certain drug-induced, and aspiration pneumonitis. Because of pandemic conditions polymerase chain reaction test was obtained and it confirmed the coronavirus disease 2019 (COVID-19) diagnosis. She received favipiravir treatment for five days. The final diagnosis was COVID-19. The neurologic findings of the patient were disappeared after treatment.
Informed Consent: Written consent was obtained from the patient.

Peer-review: Externally peer-reviewed
Financial Disclosure: The author declared that this study has received no financial support. 